Research

\title{
Malaria and anaemia among children in two communities of Kumasi, Ghana: a cross-sectional survey Lisa A Ronald ${ }^{1}$, Sarah L Kenny ${ }^{1}$, Eveline Klinkenberg1,2, Alex O Akoto ${ }^{3}$, Isaac Boakye ${ }^{3}$, Guy Barnish ${ }^{1}$ and Martin J Donnelly*1
}

Address: ${ }^{1}$ Liverpool School of Tropical Medicine, Pembroke Place, Liverpool, UK, ${ }^{2}$ International Water Management Institute (IWMI), Accra, Ghana and ${ }^{3}$ Kwame Nkrumah University of Science and Technology and Komfo Anokye Teaching Hospital, Kumasi, Ghana

Email: Lisa A Ronald - ronaldla@shaw.ca; Sarah L Kenny - sarahlkenny@yahoo.co.uk; Eveline Klinkenberg - eklinkenberg@healthnettpo.org; Alex O Akoto - alexosei_akoto@yahoo.com; Isaac Boakye - au347kb@gmail.com; Guy Barnish - gbarnish@liv.ac.uk; Martin J Donnelly* - mjames@liv.ac.uk

* Corresponding author

Published: 09 November 2006

Malaria Journal 2006, 5:105 doi:10.1 I86/1475-2875-5-105

This article is available from: http://www.malariajournal.com/content/5/I/105

(C) 2006 Ronald et al; licensee BioMed Central Ltd.

This is an Open Access article distributed under the terms of the Creative Commons Attribution License (http://creativecommons.org/licenses/by/2.0), which permits unrestricted use, distribution, and reproduction in any medium, provided the original work is properly cited.

\begin{abstract}
Background: A survey in Kumasi, Ghana found a marked Plasmodium falciparum prevalence difference between two neighbouring communities (Moshie Zongo and Manhyia). The primary objective of this follow-up study was to determine whether this parasite rate difference was consistent over time. Secondary objectives were to compare prevalences of clinical malaria, anaemia, intestinal parasite infections, and malnutrition between these communities; and to identify potential risk factors for $P$. falciparum infection and anaemia.
\end{abstract}

Methods: A cross-sectional house-to-house survey of $P$. falciparum parasitaemia, clinical malaria, anaemia, anthropometric indices, and intestinal helminths was conducted in April-May 2005. Data collection included child and household demographics, mosquito avoidance practices, distance to nearest health facility, child's travel history, symptoms, and anti-malarial use. Risk factors for $P$. falciparum and anaemia $(\mathrm{Hb}<\| \mathrm{g} / \mathrm{dl})$ were identified using generalized linear mixed models.

Results: In total, 296 children were tested from 184 households. Prevalences of $P$. falciparum, clinical malaria, anaemia, and stunting were significantly higher in Moshie Zongo (37.8\%, $16.9 \%$, $66.2 \%$ and $21.1 \%$, respectively) compared to Manhyia (12.8\%, 3.4\%, 34.5\% and $7.4 \%$ ). Of 197 children tested for helminths, four were positive for Dicrocoelium dendriticum. Population attributable risks (PAR\%) of anaemia were $16.5 \%$ (P. falciparum) and $7.6 \%$ (malnutrition). Risk factors for $P$. falciparum infection were older age, rural travel, and lower socioeconomic status. Risk factors for anaemia were $P$. falciparum infection, Moshie Zongo residence, male sex, and younger age.

Conclusion: Heterogeneities in malariometric indices between neighbouring Kumasi communities are consistent over time. The low helminth prevalence, and the twofold higher PAR\% of anaemia attributable to $P$. falciparum infection compared to malnutrition, indicate the importance of malaria as a cause of anaemia in this urban population. 


\section{Background}

Although often considered a predominantly rural disease in Africa, malaria represents a leading cause of morbidity and mortality among many urban African populations [1]. With an estimated 200 million urban residents currently at risk for malaria [2] and a projected doubling of the African urban population by 2030 [3], an urgent need to identify risk factors for malaria in urban settings has been identified $[1,4]$.

In Africa, malaria transmission is generally lower in urban compared with rural areas $[5,6]$. This is largely attributed to such factors as lower vector density, higher human density, better quality housing and improved drainage in urban areas [7]. Urban populations are also better able to access healthcare facilities and consequently suffer lower malaria morbidity and mortality [5]. Malaria risk is often unevenly distributed across urban environments, with heterogeneities in malariometric indices measured between and within many cities $[8,9]$. Evidence is also accumulating that in urban areas, the poor may be most vulnerable to the impacts of malaria [8]. While urban malaria should be amenable to targeted prevention and control programmes, a better understanding of the individual, environmental, and community-based determinants within specific communities is needed $[1,2]$.

A baseline survey of malaria in children aged 6 months to 5 years, conducted in 2002-3 in Kumasi, Ghana, found marked prevalence differences between communities [8]. Proximity to urban agriculture was not significantly associated with malaria prevalence, suggesting the importance of other risk factors. This study reports findings from a follow-up cross-sectional survey comparing two neighbouring communities (Moshie Zongo and Manhyia), which in the previous survey were found to have Plasmodium falciparum parasite rates of $32.7 \%$ and $3.8 \%$, respectively. The primary objective of this study was to determine whether the previously observed marked difference in parasite rates between the two communities was maintained. The secondary objectives were to compare prevalences of clinical malaria, anaemia, intestinal helminths, and malnutrition between these communities, and to identify risk factors for $P$. falciparum infection and anaemia.

\section{Methods}

Kumasi is the second-largest city in Ghana, with a population of 1.2 million [10]. Located in the Ashanti region of central Ghana, the climate is semi-humid tropical, with peak rainfall between April and June.

\section{Sample selection}

A cross-sectional house-to-house survey was carried out in Moshie Zongo and Manhyia during April and May 2005. Sampling was conducted between 14:00 and 19:00 and alternated on an approximately weekly basis between communities. Cluster starting points were identified based on proximity to specific landmarks (i.e., roads, intersections, and prominent buildings), with the whole area of each community included to gain a geographically representative sample of the community. A house was defined as any housing structure where one or more families were residing. The first house was selected randomly in each cluster, followed by the selection of every fifth house until a minimum cluster target of 10 children was reached. Voluntary written consent was obtained from primary carers prior to data collection. All children in the target age range present at the time of sampling were eligible to participate. The location of each sampled house was recorded using a handheld GPS receiver. A minimum sample size of 108 children per community was calculated using Epilnfo v.3.2.2 (CDC, Atlanta), based on detection of a $25 \%$ difference in $P$. falciparum parasite rates between the two communities (with a 95\% confidence interval and power of 90\%) and multiplied by 2 for a design effect. The study received ethical approval from the Liverpool School of Tropical Medicine and the Faculty of Medicine, Kwame Nkrumah University of Science and Technology, Kumasi.

\section{Data collection}

Data about household demographics, assets and house construction, together with the carer's knowledge about malaria and use of mosquito avoidance methods, were collected by questionnaire. Age, sex, recent rural travel, symptom history, and recent anti-malarial use were recorded for each child. The presence of $P$. falciparum parasitaemia was determined using a Rapid Diagnostic Test (RDT) (Paracheck ${ }^{\circledast}$, Orchid Biomedical Systems, India). Haemoglobin $(\mathrm{Hb})$ concentrations were measured using a HemoCue system (HemoCue, Sweden). Axillary temperature was measured by digital thermometer. Clinical malaria was defined as presence of $P$. falciparum, with a current axillary temperature of $\geq 37.5^{\circ} \mathrm{C}$ and/or a reported fever history during the previous 48 hours. Anthropometric measurements included height, weight, and mid-upper arm circumference (MUAC). Stool samples were collected at the time of the haematological and anthropometric sampling or the following day. Faecal samples were preserved in $10 \%$ formal saline. A volumetric dilution procedure was used to analyse the stool samples for intestinal helminths [11].

Socio-economic status (SES) was calculated for each household using World Bank asset scores for Ghana, based on ownership of a television, radio, refrigerator, car, motorcycle, bicycle, farm, electricity in house, ceiling, floor cover, and number of individuals/sleeping room [12]. The anthropometric indices height-for-age (HA), weight-for-age (WA), weight-for-height (WH), and 
MUAC-for-height were expressed as Z-scores in relation to the $1978 \mathrm{CDC} / \mathrm{WHO}$ normalized version of the 1977 NCHS reference curve (EpiInfo v3.3, CDC). Children were classified as stunted, underweight, wasted, or having low MUAC-for-height if the HA, WA, WH, or MUAC-for height scores were $<-2$ below the reference mean, respectively. A child was identified as being malnourished if $\mathrm{s} /$ he scored $<-2$ in one of the HA, WA, or WH indices.

A list of all government hospitals and primary care clinics in the surrounding area was obtained from the Kumasi Metro Director of Health and verified by the Manhyia District Hospital Administrator (the main catchment hospital for both communities). The location of each health facility was mapped using a GPS. Straight-line distance to the nearest health facility was used as a proxy for access to formal healthcare services and was calculated using ArcInfo v7.2.1 (ESRI Inc., USA).

\section{Data analysis}

Statistics were calculated using SPSS v11.5 (USA) and SAS v8.2 (SAS Institute Inc, Cary, USA). The proportion of anaemia cases attributed to $P$. falciparum infection and malnutrition were estimated as population attributable risk percentages (PAR\%) with 95\% confidence intervals (CI) [13]. Univariate significance tests used were Pearson's chi-square or Fisher's Exact test (for categorical variables), and for continuous variables, independent samples t-test or Mann-Whitney U test. Generalized linear mixed models were run with PROC MIXED, incorporating a SAS macro (Glimmix 800) allowing a logistic link function. Outcomes tested were presence of $P$. falciparum infection and $\mathrm{Hb}<11 \mathrm{~g} / \mathrm{dl}$. Variables not highly predictive of outcome variables $(\mathrm{p}>0.1)$ in unadjusted models were excluded from further modelling. For all models, household was included as a random effect. Final adjusted models included all variables significant at $\mathrm{p}<0.05$.

\section{Results}

Table 1 summarizes characteristics of the sampled households (97 in Manhyia, 87 in Moshie Zongo). Household characteristics were markedly different between the communities, with the exception of reported use of bednets, housescreens, and mosquito repellents/coils/sprays ( $\mathrm{p}>$ 0.05).

A total of 296 children were tested, 148 in each community (Table 2). Sample composition (sex ratio and median age) did not significantly differ between the communities ( $\mathrm{p}>0.05)$. Prevalences of $P$. falciparum $\left(X^{2}=24.45, \mathrm{p}<\right.$ $0.001)$, clinical malaria $\left(X^{2}=14.84, \mathrm{p}<0.001\right)$, and anaemia $\left(X^{2}=29.85, \mathrm{p}<0.001\right)$ were higher, and mean Hb levels lower $(\mathrm{p}<0.001)$, in Moshie Zongo compared to Manhyia. There were few cases of moderate to severe anaemia (<3\% prevalence in each community). More children from Moshie Zongo were stunted $\left(X^{2}=11.26, \mathrm{p}=0.001\right)$, had a reported history of diarrhoea $\left(X^{2}=8.64, \mathrm{p}=0.003\right)$, and had reportedly taken malaria medication in the previous two weeks $\left(X^{2}=3.95, \mathrm{p}=0.047\right)$. Fewer than $5 \%$ in either community had travelled recently to a rural area. Stools were examined for the first 197 children surveyed. With the exception of 4 children from neighbouring households in Manhyia who had Dicrocoelium dendriticum infections, no helminth eggs were found. As a consequence, stool samples were not collected from the remaining 99 children.

Significantly higher prevalence of $P$. falciparum was associated with low carer education, Northerner/Immigrant ethnicity, low SES, using coils/sprays/repellents, greater distance from a health facility, older age, and recent rural travel (Table 3). The same variables were significantly associated with higher anaemia prevalence, with the exception of younger age, and the addition of male sex, stunting, $P$. falciparum, and clinical malaria. No significant differences in $P$. falciparum or anaemia prevalence were observed with reported use of bednets or housescreens, recent antimalarial medication, wasting, underweight, or low MUAC-for-height. The proportion of fever cases with $P$. falciparum infection were $17.9 \%$ in Manhyia (5/28 fever cases) and 50.0\% in Moshie Zongo (25/50). The PAR\% of anaemia attributable to $P$. falciparum infection was $16.5 \%$ (95\%CI: 9.5-23.3), and to malnutrition was $7.6 \%$ (95\%CI: 1.4-13.9).

In adjusted models (Table 4 ), risk factors for $P$. falciparum infection included being older $(\mathrm{OR}=1.28$ per 1 -year increase), recent rural travel ( $\mathrm{OR}=23.45)$, and lower SES $(\mathrm{OR}=3.95$ per 1 -unit decrease). Significant risk factors for anaemia were $P$. falciparum infection $(\mathrm{OR}=3.92)$, Moshie Zongo residence $(\mathrm{OR}=3.76)$, male sex $(\mathrm{OR}=2.16)$, and younger age $(\mathrm{OR}=0.79$ per 1 -year increase $)$.

\section{Discussion}

This study demonstrated that the higher prevalence of $P$. falciparum among children in Moshie Zongo compared to neighbouring communities is temporally stable and not an artefact of a single study period [8]. The P. falciparum rate in Moshie Zongo was higher than recently reported rates in other urban areas; Kampala [14], Coutonou [15] and Dar es Salaam [16], though lower than rates reported in Ouagadougou [17]. Parasite rates from these latter surveys were obtained through primary school parasitaemia surveys and represent aggregated rates for communities in each school's catchment area. Further breakdown of rates by residence in Coutonou indicated a large parasitaemia rate difference (27.3\% and $9.2 \%$ ) between two intermediate zone areas [15]. Heterogeneities between neighbouring communities have also been reported in Brazzaville, where rates ranged from $5.6 \%$ to $78.9 \%$ among children 
Table I: Characteristics of sampled households, by community $(\mathbf{N}=184)$

\begin{tabular}{|c|c|c|c|}
\hline & Manhyia $(\mathrm{n}=97)$ & Moshie Zongo $(n=87)$ & P-valuel \\
\hline Caregiver education $\geq$ middle school, $\mathrm{n}(\%)$ & $75(77.3 \%)$ & $28(32.2 \%)$ & $<0.001^{* * *}$ \\
\hline Ethnicity Northerner/Immigrant, n (\%) & $18(18.6 \%)$ & $65(74.7 \%)$ & $<0.001^{* * *}$ \\
\hline Socioeconomic score, mean (standard deviation) ${ }^{2}$ & $2.07(0.73)$ & $1.25(0.70)$ & $<0.001 * * *$ \\
\hline House without ceiling, n (\%) & $5(5.2 \%)$ & $17(19.5 \%)$ & $0.003^{* *}$ \\
\hline Number of people per sleeping room, median (range) & $4(2,9)$ & $5(I, I I)$ & $0.020 *$ \\
\hline Reported use of mosquito repellents/coils/spray, n (\%) & $63(64.9 \%)$ & $67(77.0 \%)$ & 0.073 \\
\hline Reported use of bednet, n (\%) & $15(15.5 \%)$ & $21(24.1 \%)$ & 0.139 \\
\hline Reported use of housescreens, n (\%) & II (II.3\%) & $4(4.6 \%)$ & 0.095 \\
\hline Metres to nearest health facility, median (range) & $|3|(26,345)$ & $237(74,436)$ & $<0.001^{* * *}$ \\
\hline Metres to nearest government hospital, median (range) & $730(241,990)$ & $2344(1958,2550)$ & $<0.001^{* * *}$ \\
\hline
\end{tabular}

I. ${ }^{*} \mathrm{p}<0.05$, ** $\mathrm{p}<0.01$, *** $\mathrm{p}<0.001$

2. Calculated with World Bank asset scores for Ghana [12]

aged 5-9 years in 4 urban communities [9]. This study adds to the growing body of evidence that malaria transmission can vary widely across cities and highlights the importance of targeting interventions towards specific communities [1].

The finding that recent rural travel was associated with increased $P$. falciparum prevalence has been similarly reported among other urban populations, including Dar es Salaam [16], Abidjan [18], Lusaka [19], and previously in Kumasi [8]. However, few children from either study community had travelled recently, which suggests that most infections were obtained through local transmission. High $P$. falciparum prevalence has been recorded in rural areas of the surrounding Ashanti region [20] and Northern Ghana [21]. Urban residents who travel to these areas could be at high risk for infection, as well as at higher risk for more severe outcomes following infection if functional immunity is inadequately developed, and may become sources of infection when back home [22]. Promoting increased vigilance in the use of mosquito avoidance methods and/or prophylactic treatment among urban residents who travel to endemic rural areas could be an effective target for reducing some subsequent transmission within urban areas.

Two-thirds of the Moshie Zongo children sampled in our study were anaemic (an approximately two-fold higher prevalence than found among children in Manhyia). Prevalence of severe anaemia was low in both communities. When restricted to children under 5 years, the anaemia prevalence in the present study was comparable to the

Table 2: Test results of children sampled, by community $(N=296)$

\begin{tabular}{|c|c|c|c|}
\hline & Manhyia $(n=148)$ & Moshie Zongo $(n=148)$ & P-value ${ }^{l}$ \\
\hline Female sex, $\mathrm{n}(\%)$ & $74(50.0 \%)$ & $84(56.8 \%)$ & 0.244 \\
\hline Age in years, median (range) & $5(1,9)$ & $5(1,9)$ & 0.571 \\
\hline Presence of $P$. falciparum parasitaemia, $n(\%)$ & $19(12.8 \%)$ & $56(37.8 \%)$ & $<0.001^{* * *}$ \\
\hline Axillary temp $\geq 37.5^{\circ} \mathrm{C}$ or reported fever past 48 hours & $28(18.9 \%)$ & $50(33.8 \%)$ & $0.004 * *$ \\
\hline Clinical malaria, n (\%) ${ }^{2}$ & $5(3.4 \%)$ & $25(16.9 \%)$ & $<0.00 I^{* * *}$ \\
\hline Haemoglobin level in $\mathrm{g} / \mathrm{dl}$, mean (standard deviation) & $11.3(1.28)$ & $10.5(1.25)$ & $<0.001^{* * * *}$ \\
\hline Any anaemia: $\mathrm{Hb}<\mathrm{II}$ g/dl, n (\%) & $51(34.5 \%)$ & $98(66.2 \%)$ & $<0.00 I^{* * *}$ \\
\hline Moderate to severe anaemia: $\mathrm{Hb}<8 \mathrm{~g} / \mathrm{dl}, \mathrm{n}(\%)$ & $3(2.0 \%)$ & $4(2.7 \%)$ & 1.000 \\
\hline Malnourished (stunted, wasted, or underweight), n (\%) & $28 / 147(19.0 \%)$ & $40 / 147(27.2 \%)$ & 0.097 \\
\hline Stunted (height-for-age Z-score $<-2$ ref mean), n (\%) & II $(7.4 \%)$ & $31 / 147(21.1 \%)$ & $0.001^{* *}$ \\
\hline Underweight (weight-for-height Z-score < -2), n (\%) & $15(10.1 \%)$ & $19 / 147$ (12.9\%) & 0.453 \\
\hline Wasted (weight-for-age Z-score < -2), n (\%) & $8 / 147(5.4 \%)$ & $8 / 146(5.5 \%)$ & 0.989 \\
\hline Low MUAC-for-height (Z-score <-2), n (\%) ${ }^{3}$ & $7(4.7 \%)$ & $9 / 147(6.1 \%)$ & 0.597 \\
\hline Intestinal helminths, $\mathrm{n}(\%)^{4}$ & $4 / 98(4.1 \%)$ & $0 / 99(0.0 \%)$ & 0.059 \\
\hline Reported history of diarrhoea in past 48 hours, $n$ (\%) & $28(\mid 8.9 \%)$ & $50 / 147(34.0 \%)$ & $0.003 * *$ \\
\hline Rural travel in past 3 weeks, $n$ (\%) & $4(2.7 \%)$ & $6(4.1 \%)$ & 0.520 \\
\hline Reported malaria medication in past 2 weeks, $n(\%)$ & $31(20.9 \%)$ & $46(31.1 \%)$ & $0.047^{*}$ \\
\hline
\end{tabular}

I. $* \mathrm{p}<0.05, * * \mathrm{p}<0.01, * * * \mathrm{p}<0.001$

2. P. falciparum infection with an axillary temp $\geq 37.5^{\circ} \mathrm{C}$ or reported fever past 48 hours

3. $M U A C=$ mid upper arm circumference

4. Four cases of Dicrocoelium dendriticum 
Table 3: Factors associated with $P$. falciparum infection and anaemia $(\mathrm{Hb}<I \mathrm{I} / \mathrm{gl})$, significant associations in univariate tests $(\mathbf{N}=$ 296)'

\begin{tabular}{|c|c|c|c|c|}
\hline \multirow{2}{*}{$\begin{array}{l}\text { Variables tested } \\
\text { Education } \geq \text { middle school }\end{array}$} & \multicolumn{2}{|c|}{ Prevalence of $P$. falciparum infection $(95 \% \mathrm{CI})$} & \multicolumn{2}{|c|}{ Prevalence of $\mathrm{Hb}<\mathrm{II}(95 \% \mathrm{Cl})$} \\
\hline & & & & \\
\hline No $(n=132)$ & $40.9 \%$ & $(32.5,49.3)^{* * *}$ & $63.6 \%$ & $(55.4,71.8)^{* * *}$ \\
\hline Yes $(n=164)$ & $12.8 \%$ & $(7.7,17.9)$ & $39.6 \%$ & $(32.1,47.1)$ \\
\hline \multicolumn{5}{|l|}{ Ethnic group } \\
\hline Akan/Ga/Ewe $(n=167)$ & $16.2 \%$ & $(10.6,21.8)^{* * *}$ & $35.9 \%$ & $(28.6,43.2)^{* * *}$ \\
\hline North/Immigrant $(\mathrm{n}=129)$ & $37.2 \%$ & $(28.9,45.5)$ & $69.0 \%$ & $(61.0,77.0)$ \\
\hline \multicolumn{5}{|l|}{ Socioeconomic score ${ }^{2}$} \\
\hline Lowest $(n=80)$ & $47.5 \%$ & $(36.6,58.4)^{* * *}$ & $67.5 \%$ & $(57.2,77.8)^{* *}$ \\
\hline Middle $(\mathrm{n}=109)$ & $26.6 \%$ & $(18.3,34.9)$ & $47.7 \%$ & $(38.3,57.1)$ \\
\hline Highest $(n=107)$ & $7.5 \%$ & $(2.5,12.5)$ & $40.2 \%$ & $(30.9,49.5)$ \\
\hline \multicolumn{5}{|l|}{ Use repellents/coils/sprays } \\
\hline No $(n=83)$ & $15.7 \%$ & $(7.9,23.5)^{*}$ & $41.0 \%$ & $(30.4,51.6)^{*}$ \\
\hline Yes $(n=2 \mid 3)$ & $29.1 \%$ & $(23.0,35.2)$ & $54.0 \%$ & $(47.3,60.7)$ \\
\hline \multicolumn{5}{|l|}{ Nearest health facility ${ }^{3}$} \\
\hline$<150 m(n=97)$ & $12.4 \%$ & $(5.8,19.0)^{* * *}$ & $45.4 \%$ & $(35.5,55.3)^{* *}$ \\
\hline $150-250 m(n=\mid 12)$ & $26.8 \%$ & $(18.6,35.0)$ & $42.9 \%$ & $(33.7,52.1)$ \\
\hline$\geq 250 m(n=87)$ & $37.9 \%$ & $(27.7,48.1)$ & $65.5 \%$ & $(55.5,75.5)$ \\
\hline \multicolumn{5}{|l|}{ Child sex } \\
\hline Male $(n=138)$ & $24.6 \%$ & $(17.4,31.8)$ & $58.0 \%$ & $(49.8,66.2)^{*}$ \\
\hline Female $(n=158)$ & $25.9 \%$ & $(19.1,32.7)$ & $43.7 \%$ & $(36.0,51.4)$ \\
\hline \multicolumn{5}{|l|}{ Child age group } \\
\hline $1-3$ years $(n=108)$ & $15.7 \%$ & $(8.8,22.6)^{* *}$ & $61.1 \%$ & $(51.9,70.3)^{* *}$ \\
\hline 4-6 years $(n=106)$ & $34.0 \%$ & $(25.0,43.0)$ & $51.9 \%$ & $(42.4,61.4)$ \\
\hline $7-9$ years $(n=82)$ & $26.8 \%$ & $(17.2,36.4)$ & $34.1 \%$ & $(23.8,44.4)$ \\
\hline \multicolumn{5}{|l|}{ Rural travel, past 3 weeks } \\
\hline No $(n=286)$ & $23.8 \%$ & $(18.9,28.7)^{* *}$ & $49.3 \%$ & $(43.5,55.1)$ \\
\hline Yes $(n=10)$ & $70.0 \%$ & $(41.6,98.4)$ & $80.0 \%$ & $(55.2,100)$ \\
\hline \multicolumn{5}{|l|}{$\begin{array}{l}\text { Malnourished(stunted, wasted or } \\
\text { underweight) }\end{array}$} \\
\hline No $(n=226 / 294)$ & $24.8 \%$ & $(19.2,30.4)$ & $46.5 \%$ & $(40.0,53.0)^{*}$ \\
\hline Yes $(n=68 / 294)$ & $26.5 \%$ & $(16.0,37.0)$ & $63.2 \%$ & $(51.7,74.7)$ \\
\hline \multicolumn{5}{|c|}{ Stunted (height-for-age Z-score $<-2$ ) } \\
\hline No $(n=253 / 295)^{\circ}$ & $23.7 \%$ & $(18.5,28.9)$ & $47.0 \%$ & $(40.8,53.2)^{* *}$ \\
\hline Yes $(n=42 / 295)$ & $33.3 \%$ & $(19.0,47.6)$ & $71.4 \%$ & $(57.7,85.1)$ \\
\hline \multicolumn{5}{|l|}{ P. falciparum infection } \\
\hline No $(n=22 I)$ & & $\mathrm{n} / \mathrm{a}$ & $42.1 \%$ & $(35.6,48.6)^{* * *}$ \\
\hline Yes $(n=75)$ & & & $74.7 \%$ & $(64.9,84.5)$ \\
\hline \multicolumn{5}{|l|}{ Clinical malaria ${ }^{4}$} \\
\hline No $(n=266)$ & & $\mathrm{n} / \mathrm{a}$ & $47.0 \%$ & $(41.0,53.0)^{* *}$ \\
\hline Yes $(n=30)$ & & & $80.0 \%$ & $(65.7,94.3)$ \\
\hline
\end{tabular}

I. $* \mathrm{p}<0.05, * * \mathrm{p}<0.01$, ***p $<0.001$

2. Based on World Bank asset scores for Ghana [12]: lowest (scores $=0,1)$, middle (2), highest (3.4)

3. Health facility $=$ government hospital or primary care clinic

4. Clinical malaria: $P$. falciparum with reported fever in past 48 hours and/or current axillary temperature $\geq 37.5^{\circ} \mathrm{C}$

previous Kumasi survey [8], and to the 2003 Ghana Demographic and Health Survey for urban residents $(67.8 \%)[10]$. Demonstration of heterogeneity in anaemia rates within cities underscores the importance of targeting anaemia prevention programs to both rural and urban populations, and of targeting interventions to specific urban communities.

Anaemia is often caused by a combination of malnutrition, helminth infections, infectious diseases, and haemoglobinopathies $[23,24]$. Significant reductions in anaemia prevalence have been demonstrated following malaria control programs in stable endemic areas, and usefulness of anaemia as an indicator of malaria burden and malaria control progress will depend on its specificity [24]. In lower transmission urban areas, malaria may make a less significant contribution to anaemia than other factors. The PAR\% estimates indicated that approximately onesixth of anaemia cases were attributable to $P$. falciparum infections, and $P$. falciparum infection was strongly associated with anaemia after adjustment for other factors. This suggests that $P$. falciparum infection is an important deter- 
Table 4: Unadjusted and adjusted odds ratios (with $95 \%$ confidence intervals)' for predictors of $P$. falciparum infection and $\mathrm{Hb}<\mathrm{I}$ I g/dl

\begin{tabular}{|c|c|c|}
\hline & Unadjusted models ${ }^{2}$ OR $(95 \% \mathrm{Cl})$ & Adjusted- final model OR $(95 \% \mathrm{Cl})$ \\
\hline \multicolumn{3}{|c|}{ Model I: $P$. falciparum infection } \\
\hline Rural travel past 3 weeks & $12.80(2.20,74.46)^{* *}$ & $23.45(3.28,167.75)^{* *}$ \\
\hline Socioeconomic score ${ }^{2}$ & $3.22(1.95,5.32)^{* * *}$ & $3.95(2.26,6.90)^{* * *}$ \\
\hline Child age, in years & $1.22(1.08,1.38)^{* *}$ & $1.28(1.13,1.45)^{* * * *}$ \\
\hline \multicolumn{3}{|l|}{ Model 2: $\mathrm{Hb}<\mathrm{I} \mathbf{g} / \mathrm{dl}$} \\
\hline P. falciparum infection & $3.94(2.17,7.15)^{* * *}$ & $3.92(2.04,7.54)^{* * *}$ \\
\hline Moshie Zongo residence & $3.80(2.29,6.30)^{* * *}$ & $3.76(2.16,6.56)^{* * *}$ \\
\hline Child male & $1.83(1.13,2.97)^{*}$ & $2.16(1.28,3.66)^{* *}$ \\
\hline Child age, in years ${ }^{2}$ & $0.84(0.76,0.93)^{* * *}$ & $0.79(0.71,0.88)^{* * *}$ \\
\hline
\end{tabular}

1. Households were included as a random effect for all models, ${ }^{*} \mathrm{p}<0.05$, **p $<0.01$, *** $\mathrm{p}<0.001$

2. Child age (from I to 9 years) and socioeconomic score (from 3: highest to 0 : lowest) are included in models as continuous variable

minant of anaemia among these Kumasi children and that anaemia may represent a useful indicator for malaria control progress in these communities.

In comparison with these Ghanaian study populations, a higher prevalence of stunting but similar prevalence of wasting was found among urban Zairian children [25]. In these children from Kumasi, malnutrition (stunting, in particular) was significantly associated with anaemia in univariate tests. Stunting has been previously associated with more severe occurrence of malarial anaemia [26], and it is hypothesized that nutritional inadequacies causing stunting and underweight also impair host immunity, further exacerbating the effects of malaria $[26,27]$. In contrast, the low prevalence of intestinal helminths was surprising, compared to higher rates reported in other urban areas [25]. Parasitology laboratory records (1999-2005) from the Kumasi Komfo Anokye Teaching Hospital revealed similar low rates of intestinal helminths: of the 1,181 children aged 1-9 years tested for intestinal parasites over this period, only $164(13.9 \%)$ were positive for one or more parasites (including 10 with hookworm, $8 \mathrm{~A}$. lumbricoides, and $1 \mathrm{~T}$. trichiura). Kumasi is exposed to problems of crowding and sewage disposal, which are often associated with increased risk of helminth infections [28]. One explanation for the low prevalence of helminth infections in Kumasi could be that many parents may be regularly de-worming their children (as reported anecdotally), however, further investigation is needed to confirm these results.

The Paracheck-Pf RDTs used in this survey detect the presence ofHistidine Rich Protein 2 (HRP-2), a water soluble protein produced by asexual stages and young gametocytes of $P$. falciparum [29]. The benefits of using Paracheck Pf RDTs in community-based surveys are their high sensi- tivity at low levels of parasitaemia (> 150 parasites/ $\mu$ ) and high specificity to $P$. falciparum, and that they provide results quickly (within 15 minutes) [30]. One limitation of HRP-2-based RDTs is that HRP-2 has been shown to persist and be detectable after the clinical symptoms of malaria have disappeared and the parasites have been cleared [31]. Surveys using RDTs detecting HRP-2 may, therefore, overestimate prevalence of current infection, representing instead a combined prevalence of current and recent infections.

Twenty-five percent (25.3\%) of children with P. falciparum infection and $36.7 \%$ of children with clinical malaria had reported taking an antimalarial within the previous 2 weeks. The proportion of $P$. falciparum cases with reported recent antimalarial use was higher in Moshie Zongo $(28.6 \%)$ than Manhyia (15.8\%). It is possible that some false positives were detected due to residual HRP-2, while recall bias may also have resulted in overestimation of reported antimalarial use. However, this evidence also suggests that treatments being used by some children may not be effective in clearing parasitaemia. Home treatment or reliance on informal drug shops as a primary treatment method for child malaria is reported among many urban populations [32,33]. In eastern Uganda, treatments and dosages recommended by drug shops and government health units were often incorrect, and poor caregiver compliance with prescribed dosages was common [34]. Poor quality drugs with insufficient active ingredients have also been found among informal drug vendors in Cameroon [35]. In addition, only $50 \%$ of fever cases in Moshie Zongo and $18 \%$ in Manhyia had a P. falciparum infection. As many urban caregivers in Ghana report treating all child fevers with antimalarials [10], this suggests some over-utilization of antimalarials by children without $P$. falciparum infection in our study communities. Further 
investigation is needed to determine the quality of drugs being sold in these areas and to assess patterns of drug utilization by caregivers.

In addition, this study highlights the vulnerability of the urban poor to the impact of malaria, as a strong association was found between SES and disease prevalence. Disaggregating the mechanisms through which poverty acts is challenging due to the complex interactions of factors [36]. The SES measure was a composite and could partly reflect greater exposure to infected mosquitoes through poor quality house construction, or greater infection risk due to crowding [36]. Among sampled households, Moshie Zongo residents lived further on average to the nearest health facility, and more than $1 \mathrm{~km}$ further to the nearest government hospital. Studies in rural areas have found an association with distance to health clinics and treatment patterns for child malaria $[37,38]$, however, the influence of distance on treatment choice in urban areas is not well-documented. It is possible that distance to health facilities in our study reflected a proxy measure for other factors which differed between the two communities. Furthermore, sample sizes were calculated to detect a difference in $P$. falciparum prevalence, and as a consequence, this study may have more limited power to assess differences in other factors between the communities. No data were collected to differentiate clinics by ownership type, treatment costs, or the range of services provided by each clinic; however, all of the clinics operating in Moshie Zongo were private clinics, which could have different treatment fees than government facilities. Good access to health services and timely provision of effective drug treatment is a self-targeting intervention, yet the costs of treatment and prevention often preclude the poorest people from using them [39]. Greater distance to affordable health services could result in delayed seeking of treatment. Further research is needed to determine if treatment-seeking behaviours in these communities differ and to what extent these behaviours are associated with availability of different types of health services.

\section{Conclusion}

Heterogeneities in malariometric indices between neighbouring urban communities of Kumasi are consistent over time. The low prevalence of intestinal helminths, and the twofold higher PAR\% of anaemia attributable to $P$. falciparum infection compared to malnutrition, indicate the importance of malaria as a cause of anaemia in this urban population. Further investigation is needed to determine if treatment-seeking behaviours in these two communities differ and to what extent behaviours are associated with availability of different types of health services.

\section{Authors' contributions}

LAR helped to design the study, performed data collection, analysis and drafted the manuscript. SLK helped to design the study, performed data collection and analysis. EK helped to design the study and assisted with the analysis. AOA helped to design the study and supervised data collection. IB performed data collection. GB designed and supervised the study. MJD conceived of the study, and participated in its design and coordination. All authors read and approved the final manuscript.

\section{Competing interests}

The author(s) declare that they have no competing interests.

\section{Acknowledgements}

The authors gratefully thank our medical technologist, Julius Amegah Kwabena, for his hard work in the field; the Assembly members, study participants and community members for their support and participation in this study; and Orchid Biomedical Systems for their generous provision of RDTs. We also thank Dr. Philip McCall of LSTM; Dr. Pay Dreschel, Ben Keraita and Osei Boateng Kwame of IWMI for project support; and Dr. Daniel Ansong, Mavis Asirifi-Dankwah, Victoria Osman and Kim FindlayCooper for field assistance. This study was partially financed by the Department for International Development-funded Malaria Knowledge Programme of the Liverpool School of Tropical Medicine. However, the Department for International Development can accept no responsibility for any information or views expressed. The project is a contributed project to the Consultative Group of International Agricultural Research Centres Systemwide Initiative on Malaria and Agriculture. Lisa Ronald received funding support through the Gunther Foundation and the Hesketh Leverhulme Fund, Liverpool School of Tropical Medicine.

\section{References}

I. Donnelly MJ, McCall PJ, Lengeler C, Bates I, D'Alessandro U, Barnish G, Konradsen F, Klinkenberg E, Townson H, Trape JF, Hastings IM, Mutero $C$ : Malaria and urbanization in sub-Saharan Africa. Malar J 2005, 4: I-5.

2. Keiser J, Utzinger J, de Castro MC, Smith TA, Tanner M, Singer BH: Urbanization in Sub-Saharan Africa and implication for malaria control. Am J Trop Med Hyg 2004, 7 I: I I 8-I27.

3. Urban and Rural Health Areas 2003 (Report \# ST/ESA/SER.A/23I) New York, USA: United Nations Population Division, Department of Economic and Social Affairs; 2004.

4. Klinkenberg E, McCall PJ, Hastings IM, Wilson MD, Amerasinghe FP, Donnelly MJ: Malaria and irrigated crops, Accra, Ghana. Emerg Infect Dis 2005, I I:1290-I293.

5. Hay SI, Guerra CA, Tatem AJ, Atkinson PM, Snow RW: Urbanization, malaria transmission and disease burden in Africa. Nat Rev Microbiol 2005, 3:81-90.

6. Omumbo JA, Guerra CA, Hay SI, Snow RW: The influence of urbanization on measures of Plasmodium falciparum infection prevalence in East Africa. Acta Trop 2005, 93: II-2I.

7. Lindsay SW, Campbell H, Adiamah JH, Greenwood AM, Bangali JE, Greenwood BM: Malaria in a peri-urban area of The Gambia. Ann Trop Med Parasitol 1990, 84:553-562.

8. Klinkenberg E, McCall PJ, Wilson MD, Akoto AO, Amerasinghe FP, Bates I, Verhoeff FH, Barnish G, Donnelly MJ: Urban malaria and anaemia: a cross-sectional survey of two cities in Ghana. Trop Med Int Health 2006, I I:578-588.

9. Trape JF: Malaria and urbanization in Central Africa: The example of Brazzaville. Part IV: Parasitological and serological surveys in urban and surrounding rural areas. Trans $R$ Soc Trop Med Hyg 1987, 8 I (Suppl 2):26-33. 
10. Ghana Demographic and Health Survey 2003 Calverton, Maryland: Ghana Statistical Service (GSS), Noguchi Memorial Institute for Medical Research (NMIMR), and ORC Macro; 2004.

II. Ashford RW, Barnish G, Viney ME: Strongyloides fuelleborni kellyi : infection and disease in Papua New Guinea. Parasitol Today 1992, 8:3|4-318.

12. Gwatkin DR, Rusten S, Johnson K, Paude RP, Wagstaff A: Socioeconomic differences in health nutrition and population in Ghana Washington, USA: World Bank; 2000.

13. Walter SD: Calculation of attributable risks from epidemiological data. Int J Epidemiol 1978, 7:| 75- 182.

14. Davis IC, Clark TD, Kemble SK, Talemwa N, Njama-Meya D, Staedke SG, Dorsey G: Longitudinal study of urban malaria in a cohort of Ugandan children: description of study site, census and recruitment. Malar J 2006, 5: I- I I.

15. Wang SJ, Lengeler C, Smith TA, Vounatsou P, Akogbeto M, Tanner M: Rapid urban malaria appraisal (RUMA) IV: Epidemiology of urban malaria in Coutonou (Benin). Malar J 2006, 5:.

16. Wang SJ, Lengeler C, Mtasiwa D, Mshana T, Maname L, Maro G, Tanner M: Rapid urban malaria appraisal (RUMA) II: Epidemiology of urban malaria in Dar es Salaam (Tanzania). Malar J 2006, 5:

17. Wang SI, Lengeler C, Smith TA, Vounatsou P, Diadie DA, Pritroipa X Convelbo N, Kientga M, Tanner M: Rapid urban malaria appraisal (RUMA) I: Epidemiology of urban malaria in Ougadougou. Malar J 2005, 4:.

18. Wang SJ, Lengeler C, Smith TA, Vounatsou P, Cisse G, Tanner M: Rapid urban malaria appraisal (RUMA) III: Epidemiology of urban malaria in the municipality of Yopougon (Abidjan). Malar J 2006, 5:

19. Ng'andu N, Watts WE, Wray JR, Chela C, Zulu B: Some risk factors for transmission of malaria in a population where control measures were applied in Zambia. East Afr Med J 1989, 66:728-737.

20. Browne ENL, Frimpong E, Sieverstsen J, Hagen J, Hamelmann C, Dietz K, Horstmann RD, Burchard GD: Malariometric update for the rainforest and savanna of Ashanti region, Ghana. Ann Trop Med Parasitol 2000, 94:15-22.

21. Koram KA, Owusu-Agyei S, Fryauff DJ, Anto F, Atuguba F, Hodgson A, Hoffman SL, Nkrumah FK: Seasonal profiles of malaria infection, anaemia, and bednet use among age groups and communities in northern Ghana. Trop Med Int Health 2003, 8:793-802

22. Robert V, Macintyre K, Keating J, Trape JF, Duchemin JB, Warren M, Beier JC: Malaria transmission in urban sub-Saharan Africa. Am J Trop Med Hyg 2003, 68: 169-176.

23. Crawley J: Reducing the burden of anemia in infants and young children in malaria-endemic countries of Africa: from evidence to action. Am J Trop Med Hyg 2004, 7 I (Suppl 2):25-34.

24. Korenromp EL, Armstrong-Schellenberg JRM, Williams BG, Nahlen BL, Snow RW: Impact of malaria control on childhood anaemia in Africa-a quantitative review. Tropical Medicine and International Health 2004, 9: 1050-1065.

25. Tshikuka JG, Gray-Donald K, Scott M, Olela KN: Relationship of childhood protein-energy malnutrition and parasite infections in an urban African setting. Trop Med Int Health 1997, 2:374-382

26. Verhoef H, West CE, Veenemans J, Beguin Y, Kok FJ: Stunting may determine the severity of malaria-associated anemia in African children. Pediatrics 2002, I I 0:e48.

27. Caufield LA, Richard SA, Black RE: Undernutrition as an underlying cause of malaria morbidity and mortality in children less than five years old. Am J Trop Med Hyg 2004, 7 I (Suppl 2):55-63.

28. Crompton DW, Savioli L: Intestinal parasitic infections and urbanisation. Bull World Health Organ 1993, 7 I:I-7.

29. Mboera LEG, Fanello CI, Malima RC, Talbert A, Fogliati P, Bobbio F, Molteni F: Comparison of the Paracheck-Pf ${ }^{\circledR}$ test with microscopy, for the confirmation of Plasmodium falciparum malaria in Tanzania. Ann Trop Med Parasitol 2006, 100:1 I5-122.

30. Proux S, Hkirijareon L, Ngamngonkiri C, McConnell S, Nosten F: Short communication: Paracheck-Pf: a new, inexpensive and reliable rapid test for $\mathbf{P}$. falciparum malaria. Trop Med Int Health 2001, 6:99-101.

31. Moody A: Rapid diagnostic tests for malarial parasites. Clin Microbiol Rev 2002, 15:66-78.
32. Biritwum RB, Welbeck J, Barnish G: Incidence and management of malaria in two communities of different socio-economic level, in Accra, Ghana. Ann Trop Med Parasitol 2000, 94:771-778.

33. Niama D, Dorsey G, Guwatudde D, Kigonya K, Greenhouse B, Musisi S, Kamya MR: Urban malaria: primary caregivers' knowledge, attitudes, practices and predictors of malaria incidence in a cohort of Ugandan children. Trop Med Int Health 2003 , 8:685-692.

34. Nshakira N, Kristensen M, Ssali F, Whyte SR: Appropriate treatment of malaria? Use of antimalarial drugs for children's fevers in district medical units, drug shops and homes in eastern Uganda. Trop Med Int Health 2002, 7:309-316.

35. Basco LK: Molecular epidemiology of malaria in Cameroon XIX. Quality of antimalarial drugs used for self-medication. Am J Trop Med Hyg 2004, 70:245-250.

36. Bates I, Fenton C, Gruber J, Lalloo D, Lara AM, Squire SB, Theobald $\mathrm{S}$, Thomson R, Tolhurst R: Vulnerability to malaria, tuberculosis, and HIVIAIDS infection and disease. Part I: determinants operating at individual and household level. Lancet Infect Dis 2004, 4:267-277.

37. Buor D: Analysing the primacy of distance in the utilization of health services in the Ahafo-Ano South District, Ghana. Int J Health Plann Manage 2003, I8:293-3II.

38. Schellenberg JA, Newell JN, Snow RW, Mung'ala J, Marsh K, Smith PG, Hayes RJ: An analysis of the geographical distribution of severe malaria in children in Kilifi District, Kenya. Int J Epidemiol 1998, 27:323-329.

39. Carter R, Mendis KN, Roberts D: Spatial targeting of interventions against malaria. Bull World Health Organ 2000, 78: $|40|-|4| \mid$.
Publish with Biomed Central and every scientist can read your work free of charge

"BioMed Central will be the most significant development for disseminating the results of biomedical research in our lifetime. "

Sir Paul Nurse, Cancer Research UK

Your research papers will be:

- available free of charge to the entire biomedical community

- peer reviewed and published immediately upon acceptance

- cited in PubMed and archived on PubMed Central

- yours - you keep the copyright
BioMedcentral 